\title{
Psycho-social components determining the strategies of coping with stress in undergraduate Polish nursing students
}

\author{
Iwona Bodys-Cupak 모, Anna Majda, Anna Kurowska, Ewa Ziarko and Joanna Zalewska-Puchała
}

\begin{abstract}
Background: In order for the nursing students to fully benefit from the clinical experience, it is necessary for them to be able to handle education-related stress. It is important to establish the importance of personal resources and social determinants, that influence coping strategies in stressful situations.

Methods: The cross-sectional study was conducted among 307 nursing students. The study research tools: Perceived Stress Scale (PSS-10), Life Orientation Test - Revised (LOT-R), Generalized Self-Efficacy Scale (GSES), Satisfaction With Life Scale (SWLS), Clinical Learning Environment Inventory (CLEI - 19), Brief COPE and the original questionnaire were used.

Results: Active strategies of coping with stress were used significantly more often by the respondents with a greater sense of self-efficacy, a greater sense of life satisfaction and disposable optimism. Avoidance strategies of coping with stress were used significantly more often by the respondents with low self-efficacy, low level of disposable optimism, low sense of life satisfaction, and not a lot of teacher support. The higher was the intensity of stress experienced by students, the more often they coped by avoidance behaviour or showing helplessness.

Conclusions: All the variables had a significant impact on coping with stress: the level of perceived stress, disposable optimism, sense of self-efficacy, sense of life satisfaction, as well as satisfaction with the stay in a hospital ward, support received from the teacher and the year of the study. The results of the research have allowed the identification of the needs in the field of strengthening the personal resources of nursing students. In the future, they may be useful for the development of educational programs.
\end{abstract}

Keywords: Nursing, Student, Coping, Self-efficacy, Stress, Life satisfaction, Life optimism, Satisfaction, Support, Clinical learning environment

\section{Background}

In the last decades, awareness has grown that care over nursing students is crucial not only for their well-being and academic achievement, but is also essential in the process of preparing them to become professionals caring for others. Broadly understood emotional,

\footnotetext{
*Correspondence: i.bodys-cupak@uj.edu.pl

Department of Nursing Fundamentals, Faculty of Health Sciences, Institute of Nursing and Midwifery, Jagiellonian University Medical College, 12 Michałowskiego Str, 31-126 Krakow, Poland
}

informative, and instrumental support provided to future medical staff by teachers may have a positive impact on their psychosocial resources and thus effectively motivate them to self-develop and shape soft skills that play a large role when it comes to teamwork. Constructive interactions between university employees and students and a sense of belonging are conducive to launching various sources of support for people in difficult/problematic/stressful situations especially during education in a clinical environment [1].

C C The Author(s). 2021 Open Access This article is licensed under a Creative Commons Attribution 4.0 International License, which permits use, sharing, adaptation, distribution and reproduction in any medium or format, as long as you give appropriate credit to the original author(s) and the source, provide a link to the Creative Commons licence, and indicate if changes were made. The images or other third party material in this article are included in the article's Creative Commons licence, unless indicated otherwise in a credit line to the material. If material is not included in the article's Creative Commons licence and your intended use is not permitted by statutory regulation or exceeds the permitted use, you will need to obtain permission directly from the copyright holder. To view a copy of this licence, visit http://creativecommons.org/licenses/by/4.0/ The Creative Commons Public Domain Dedication waiver (http://creativecommons.org/publicdomain/zero/1.0/) applies to the data made available in this article, unless otherwise stated in a credit line to the data. 
It is characteristic for the education system to enforce the progress in learning in terms of knowledge and skills. It is inextricably linked with the stress experienced by the students. Every student experiences stress from the beginning of education [2]. Nursing students deal with various difficult situations, especially during practical classes in health care facilities [3]. Many studies have confirmed the occurrence of such stressful situations [4-9].

During undergraduate studies, nursing students in Poland spend over $50 \%$ of the hours of the 4800 -h education program in health care units. They are exposed to various stressors directly related to the clinical learning environment. i.e. patient care, including, in particular, the performance of the caring activities and medical procedures, contact with the patient's family, and cooperation with members of the interdisciplinary team.

Lazarus and Folkman (1984) stress theory was chosen as the guiding concept for the present study because it describes the nature of stress and the relationship between stress, coping and the environment [10]. Coping with stress is a positive factor that leads to growth and development, and stimulates new ventures. Coping with stress in the concept of R. Lazarus and co-authors is "the cognitive and behavioural efforts of the subject aimed at meeting specific external and/or internal requirements that are assessed by the subject as checking or exceeding personal resources" ([11], pp.572). This means that the specific remedial activity of a person is a consequence of the assessment of the situation and one's own abilities. Therefore, the choice strategy of coping with stress is the result of the analysis of the situation and dispositional features referred to as styles [12]. Carver, Scheier, and Weintraub were the first to distinguish between the strategy and style of coping with stress they treat strategy as situational and style as dispositional coping [13] This study focused on the assessment of situational coping with stress.

The methods of coping with stress applied by the students in stressful situations change in the education process [14]. Research has shown that students use various coping strategies from avoidance behaviours to strategies based on active action, e.g. problem solving [7, $15,16]$. Lack of skills related to coping with stress can cause depression, anxiety, behavioural problems, irritability, social withdrawal, and physical illness [5, 17-20]. According to Juczyński, the course of the process of coping with stress is determined by the personal resources possessed and the social support network [21].

Self-efficacy, level of disposable optimism, and life satisfaction are factors that correlate with the way of coping with stress. Self-efficacy has been recognized as a variable that moderates stress and methods of coping with it $[22,23]$, as well as preventing professional burnout [24].
Research by Delany et al. [25] suggests that enhancing positive coping strategies is an important aspect of building self-efficacy and cognitive control, as well as greater self-awareness of students as learners and future professionals. The students' self-efficacy and choice of strategies of coping with stress are related to resilience and professional burnout.

The impact of optimism on coping with stress and quality of life has been described in earlier studies by Chang and Chan [26], as well as Cruz et al. [27]. In other words, that faith in achieving a goal promotes active forms of coping, while a lack of faith in success leads to abandonment of action.

An important element shaping the ways of coping with stress is the learning environment, especially the clinical environment. Students' satisfaction with the classes taking place in the hospital ward depends on the stress they experience and the ability to cope with it [28, 29]. Life satisfaction is, in turn, a factor dependent on how nursing students cope with stress, as shown in research by Lardier et al. [29].

The support provided by the teacher during classes in the clinical environment determines the learning outcomes achieved by students and shapes attitudes towards the future profession [30]. Properly provided support significantly helps students reformulate the experience, facilitates the flexible use of internal and external coping resources, and allows them to reflect on themselves and take care of themselves, all of which help to increase their resilience [31].

Due to the fact that the effectiveness of each person is largely dependent on the intensiveness of stress, it can also be said that the ability to cope with stress is an important factor influencing the achievement of success in education. In Polish literature, there are no studies on the impact of the culture/environment of upbringing and teaching on the shaping of strategies for coping with stress among nursing students, therefore the present research was undertaken. The results of the research conducted among nursing students will allow for the verification of previous research results, finding differences, and the presentation of the issue in a different socio-cultural context.

\section{Methods}

\section{Study design}

The research was a cross-sectional study, carried out using a diagnostic survey, estimation, and scaling method. The aim of the study was to assess the impact of selected personal variables (sense of optimism, selfefficacy, life satisfaction) and satisfaction with clinical classes (teacher support, satisfaction with staying in a hospital ward) as well as the intensity of perceived stress 
and the year of the study, on strategies of coping with the stress of nursing students during clinical classes.

\section{Setting \& participants}

The study used a purposeful selection of participants to the study group. The research was conducted among full-time undergraduate nursing students at the Jagiellonian University Medical College (a leading academic centre in southern Poland). Sample size was calculated on G*Power 3.1.9.2, which revealed that a minimum of 207 participants was needed to perform a regression analysis with a median effect size of 0.15 , significance level of 0.05 , statistical power of 0.95 .

\section{Measurements tools}

The research used: Life Orientation Test - Revised (LOT-R), Generalized Self-Efficacy Scale (GSES), Satisfaction With Life Scale (SWLS), Clinical Learning Environment Inventory (CLEI-19), and Perceived Stress Scale (PSS-10), Brief COPE and questionnaire developed by members of the research team, which included among others questions about socio-demographic variables.

Life Orientation Test - Revised (LOT-R) by Scheier, Carver and Bridges [32]. The adaptation to Polish conditions was made by Poprawa and Juczyński. The LOT-R tool consists of the 10 items, 3 items measure optimism, 3 items measure pessimism, and 4 items serve as fillers. Respondents rate each item on a 4-point scale: $0=$ strongly disagree, $1=$ disagree, $2=$ neutral, $3=$ agree, and $4=$ strongly agree. The respondent can get from 0 to 24 points. The higher the result, the higher the level of disposable optimism presented by the respondent. Raw results are analysed in relation to the sten scale, where a score of 1-4 is low (indicating a tendency towards pessimism), and the score of 7-10 is high (tendency towards a positive attitude). For the original version of the scale, the Cronbach's alpha coefficient is 0.78 , meanwhile, for the Polish version of the scale, it was similar and was equal to 0.79 [21].

Generalized Self-Efficacy Scale (GSES) measures the strength of an individual's general faith in the effectiveness of coping with difficult situations and obstacles. The tool was made by Schwarzer and Jerusalem [33]. The tool was adapted to Polish conditions by Juczyński. The scale consists of 10 statements related to various personal characteristics, which the respondent assesses as true or false in relation to himself / herself using the following scoring: 1 - "no". 2 - "rather not". 3 - "rather yes". 4 - "yes". Raw results are analysed in relation to sten norms: 1-4 (low score), 5-6 (average score), 7-10 (high score). The theoretical range of the scale was 0 to 40 points. The higher scores corresponded to higher self-efficacy. The scale is characterized by a moderately high critical accuracy and reliability. Cronbach's alpha coefficient for the scale is 0.85 . meanwhile, for the Polish version, it was equal to 0.78 [21].

Satisfaction With Life Scale (SWLS) by Diener, Emmons, Larson and Griffin [34]. Polish adaptation of the tool has been made by Juczyński. By means of this tool, it is possible to assess the general index of the person's satisfaction with life. Life satisfaction is expressed in the feeling of being satisfied with one's own achievements and conditions. The scale consists of five statements rated on a seven-point scale. The respondent assesses to what extent each statement relates to his/her life and to what extent he/she agrees with each statement in accordance with scoring from 1 ("I completely disagree") to 7 ("I completely agree"). The respondent can score from 5 to 35 points. The higher the score, the higher the sense of his/her life satisfaction. The scoring can be converted into sten scores, where scores from 1 to 4 are considered low, 5-6 average. and 7-10 high. Cronbach's alpha coefficient for the scale is 0.85 meanwhile, for the Polish version of the scale it was equal to 0.81 [21].

Clinical Learning Environment Inventory (CLEI - 19).

The CLEI-19 questionnaire by Salamonson et al. [35] allows the assessment of the support from the teacher perceived by the student in terms of learning and his student satisfaction with the work in the hospital ward. The inventory contains 19 statements, out of which 12 statements are related to the teacher support and 7 of them to satisfaction with the work in the hospital ward. In each statement, the respondent decides how much the statement is consistent with his/her feelings by selecting answers from 1 (Strongly disagree) to 5 (Strongly agree) on a 5-point Likert scale. CLEI-19 total scores range from 19 to 95 , with higher scores representing a more positive perception of the clinical learning environment [35]. Cronbach's alpha coefficient of the original version of the scale is 0.93 . In the Polish version of the scale which adaptation was carried out for the purposes of this study, Cronbach's alpha coefficient is 0.92 , for teacher support in the aspect of learning the Cronbach's alpha coefficient is 0.95 , whereas for satisfaction with hospital stay the Cronbach's alpha coefficient is 0.90 . The obtained scores indicate that the designed scale is a reliable tool (unpublished self-validation).

The 10-item Perceived Stress Scale (PSS-10) is used to assess the insensitiveness of stress related to life situation over the last month. The authors of the tool are Cohen, Kamarck and Mermelstein [36]. Adaptation of the scale to Polish conditions was carried out by Juczyński and Ogińska-Bulik. The scale contains 10 questions about subjective feelings related to personal problems and events. For each question the respondent chooses one of the answers on a 5-point scale (0 - "never"; 1 - "almost never"; 2 
- "sometimes"; 3 - "quite often"; 4 - "very often"). The overall scale score is the sum of all points, the theoretical distribution of which ranged from 0 to 40. Scores ranging between 1 and 4 are considered low, scores between 7 and 10 high, and scores between 5 and 6 average. The higher the respondent's score, the higher level of stress is experienced. The internal consistency of the original version of the scale for most subscales has an indicator close to 0.7. meanwhile, in the Polish version of the scale, it was 0.82 [37].

Brief COPE is used to assess the typical ways of reacting and feeling when experiencing stress and being in difficult situations. The tool created by Carver [13] and adapted by Juczyński and Ogińska-Bulik (called Inventory for Measuring Coping With Stress Mini-COPE) consisted of 28 theorems covering 14 strategies for coping with stress and difficult situations divided into 7 factors. i.e. Active Coping which includes the following strategies: Active coping, Planning, Positive reinterpretation; Seeking Support including Seeking emotional support and Seeking instrumental support; Helplessness including: Using psychoactive substances, Restraint coping, Self-blame; and Avoidance Behaviours including Finding other activities, Denial and Discharge, Turning to Religion, Acceptance, and Humour were treated as independent factors. For each statement the respondent selected one of four possible answers from "I almost never do this" (0 points) to "I almost always do this" (3 points). For each strategy, the score is calculated separately and the higher the score the more often the strategy is used. An in-depth analysis of the scores distinguishes three problem-focused strategies including Active Coping, Planning, Seeking Instrumental Support, and emotion-focused strategies covering Seeking Emotional Support, Turning towards Religion, and Denial. The reliability of the original version of the Inventory reaches indicators of nearly 0.70 for most scales [37].

The original questionnaire contained sociodemographic questions regarding among others: gender, age, and year of studies. It made it possible to collect information used for an in-depth characterization of the study group.

In this study, the dependent variable was the strategy of coping with stress, while the independent variables were: the level of dispositional optimism, the sense of generalised self-efficacy, the sense of life satisfaction, the intensity of the perceived stress, teacher's support, satisfaction with the stay in the hospital ward, and the year of the study.

\section{Data collection}

The study was conducted in the 2018/2019 academic year among people studying nursing at the first-degree level at the Faculty of Health Sciences Jagiellonian University Medical College.

At the design stage of the study, the criteria for inclusion in the study were established: studying nursing in full-time undergraduate studies, completion of clinical practice in hospital/clinic, and consent to participate in the study. The approval of the bioethics Committee of the Jagiellonian University was obtained prior to the research. The participants were informed about the confidentiality and anonymity of the study, that participation in the study was voluntary, and that it was possible to withdraw/refuse to cooperate at any stage of the study.

Questionnaires were distributed to the students during meetings that took place before the lectures. During the meetings, the participants were informed about the purpose of the study and the method of completing the questionnaire. Research team members distributed 450 questionnaires to all undergraduate students in the 2018/2019 academic year who met the inclusion criteria.

The participants of the study returned a total of 315 questionnaires (70\% of all 450 questionnaires distributed). Eight questionnaires were rejected due to a significant lack of data, which made the analysis impossible. Ultimately, 307 questionnaires were used for the final analysis.

\section{Statistical methods}

The analysis was performed with the use of IBM SPSS Statistics 20. The obtained raw results were entered into the database as coded data. During the analysis of the collected research material, statistical methods were used allowing for the development of results and conclusions. The analysis used the independence test $\mathrm{chi}^{2}$, the Kruskal-Wallis test, and the Spearman correlation coefficient. The choice of non-parametric tests was dictated by the lack of normal distribution of variables and the above was checked with the Kolmogorow-Smirnow and Shapiro - Wilk test. The comparison of the values of quantitative variables in the three groups was performed using the Kruskal-Wallis test. Correlation between quantitative variables was analysed using Spearman's rank correlation coefficient.

The strength of dependence was interpreted according to the following formula: $|\mathrm{r}| \geq 0.9$ - very strong correlation; $0.7 \leq|\mathrm{r}|<0.9$ - strong correlation; $0.5 \leq|\mathrm{r}|<0.7-$ medium correlation; $0.3 \leq|\mathrm{r}|<0.5$ - small correlation; $|\mathrm{r}|<0.3$ - very small correlation (negligible). The study also used linear regression carried out with the stepwise method. Regression was calculated separately for each strategy of coping with stress. The obtained raw results were entered into the database as encoded data. A significance level of 0.05 was assumed [38]. 


\section{Ethical considerations}

The research was approved by the Bioethics Committee - No. of approval: 072.6120.208.2018.

Students were informed of the confidentiality and anonymity of the study, that their participation was voluntary and that they may cease to cooperate at any time during the study.

The study was conducted in accordance with the principles of the Helsinki Declaration. All of the collected data are stored as protected files accessible according to the regulations of the General Data Protection Regulation $[39,40]$.

\section{Results}

\section{Characteristics of the study group}

The study group consisted of 307 people who met the inclusion criteria for the study, $96.1 \%$ of whom were women $(N=295)$ and $3.9 \%$ men $(N=12)$. The average age of the respondents was $20.82 \pm 1.53$. with their age ranging from $19(N=49)$ to $34(N=1)$. The average age of the women was $20.78 \pm 1.33$, while the average age of the men was $21.92 \pm 4.06 .20$ - and 21-year-olds constituted the largest age groups $(N=90$ i.e. $29.3 \%$ and $N=$ 86. i.e. $28.0 \%$ respectively) $20.2 \%$ of the participants were 22 years old $(N=62)$, and few were slightly older than 20 years old $(N=20$. i.e. 6.5\%). Freshmen constituted $40.1 \%$ of all the respondents $(N=123), 37.5 \%$ of the participants were sophomores $(N=115)$ and $22.5 \%$ were juniors $(N=69)$ (Table 1$)$.

\section{The dispositional optimism of the students - LOT-R}

A pessimistic attitude was presented by $30.0 \%$ of the students $(N=92)$. The average level of life orientation concerned $37.8 \%$ of the respondents $(N=116)$. In the case of $32.2 \%$ of people $(N=99)$ the life attitude was optimistic. The mean score of the LOT-R test was $14.43 \pm 3.80$ points and the scores were in the range of 2-24 points. Freshmen (38.21\%) had a more optimistic attitude than other groups. The most

Table 1 Sociodemographic data of the study group

\begin{tabular}{llll}
\hline Sociodemographic variables & N & \% \\
\hline Gender & woman & 295 & 96.1 \\
man & 20 & 12 & 3.9 \\
Age (years) & 21 & 90 & 29.3 \\
& 22 & 86 & 28 \\
& $>22$ & 62 & 20.2 \\
Year of the study & I & 20 & 6.5 \\
& II & 123 & 40.1 \\
& III & 115 & 37.5 \\
\hline
\end{tabular}

pessimistic attitude among the respondents was presented by juniors $(p=0.017)$ (Table 2$)$.

\section{Generalized self-efficacy of nursing students' - GSES}

Based on the GSES scale, it was found that over half of the students $(N=179$, i.e. $58.3 \%)$ had a high sense of self-efficacy. Average results were obtained by $34.2 \%$ of the respondents $(N=105)$, and low results by only $7.5 \%$ of the respondents $(N=23)$. High self-efficacy was demonstrated most often by sophomores $(65.21 \%)$ and freshmen $(62.6 \%)$, and only by $37.7 \%$ of the surveyed juniors. Low self-efficacy was demonstrated by $3.3 \%$ of freshmen, $6.1 \%$ of sophomores, and $17.4 \%$ of juniors. Average selfefficacy was demonstrated by $33.3 \%$ of freshmen, $28.7 \%$ of sophomores, and $44.9 \%$ of juniors. The differences were not statistically significant $(p=0.0002)$ (Table 3$)$.

\section{The sense of satisfaction with the life of the surveyed nursing students - SWLS}

A low level of satisfaction with life was declared by $27.0 \%$ of students $(N=83)$. Average scores were obtained by $42.0 \%$ of participants $(N=129)$ and high scores of $30.9 \%$ of respondents $(N=95)$. The average level of satisfaction with life was $20.82 \pm 5.72$ points and was in the range of 5-35 points. The average score obtained on the sten scale was $5.64 \pm 2.00$ points and was in the range of 1-10 points. A high level of satisfaction with life was demonstrated more often by sophomores $(40.86 \%)$ than by other groups of respondents. The average level of satisfaction was shown more often by freshmen (45.52\%) and juniors $(42.02 \%)$. The differences were statistically significant $(p=0.0098)$ (Table 4$)$.

Assessment of clinical learning environment - CLEI - 19 On the basis of the CLEI-19 scale, it was shown that the average summary score of teacher support in terms of learning was $31.73 \pm 10.71$ points and ranged from 12 to 53 points (scale range $12-60$ points). Satisfaction with the stay in the hospital ward as a summary score amounted to an average of $26.22 \pm 5.10$ points and ranged from 11 points to 35 points. (scale range $7-35$ points).

Taking into account the mean values of the two scales (1-5 point scale), it was possible to compare the scores. Thus, it was found that satisfaction with the stay in the hospital ward was higher $(3.75 \pm 0.73$ points $)$ than satisfaction with the teacher's support in terms of learning $(2.64 \pm 0.89$ points $)$.

It has been shown that the higher the year of studies, the higher the teacher's support factor in terms of learning. The lowest score was obtained by the freshmen $(M=1.68)$, while the sophomores $(M=3.28)$ and juniors $(\mathrm{M}=3.30)$ scored almost twice as high $(\mathrm{M}=3.30)$. The differences were statistically significant $(p<0.0001)$. 
Table 2 The dispositional optimism of the students and the year of the study

\begin{tabular}{|c|c|c|c|c|c|c|}
\hline & & & \multicolumn{3}{|c|}{ Year of the study } & \multirow[t]{2}{*}{ Total } \\
\hline & & & $\mathrm{I}$ & II & III & \\
\hline \multirow[t]{6}{*}{ Life Orientation Test -Revised (LOT-R) } & Low scores & $\mathrm{N}$ & 35 & 28 & 29 & 92 \\
\hline & & $\%$ & $28.5 \%$ & $24.3 \%$ & $42.0 \%$ & $30.0 \%$ \\
\hline & Average scores & N & 41 & 47 & 28 & 116 \\
\hline & & $\%$ & $33.3 \%$ & $40.9 \%$ & $40.6 \%$ & $37.8 \%$ \\
\hline & High scores & $\mathrm{N}$ & 47 & 40 & 12 & 99 \\
\hline & & $\%$ & $38.2 \%$ & $34.8 \%$ & $17.4 \%$ & $32.2 \%$ \\
\hline \multirow[t]{2}{*}{ Total } & & $\mathrm{N}$ & 123 & 115 & 69 & 307 \\
\hline & & $\%$ & $100.0 \%$ & $100.0 \%$ & $100.0 \%$ & $100.0 \%$ \\
\hline
\end{tabular}

$\mathrm{X} 2-\mathrm{chi}^{2}$ independence test, $\mathrm{p}-$ significance level $<0.05$.

The level of satisfaction with staying in a hospital ward among freshmen was higher than for other surveyed groups $(M=4.36)$. Sophomores and juniors were less satisfied with their stay in the hospital ward $(M=3.33$ in both groups). The scores were statistically significantly different $(p<0.0001)$ (Table 5).

\section{Intensification of stress experienced by students - PSS - 10}

The largest group among the respondents $(N=195$, i.e. $63.5 \%)$ were students who experienced high levels of stress. The average level of stress was experienced by $28.7 \%$ of respondents $(N=88)$, and a low level of stress by $7.8 \%(N=24)$. The mean score was $21.15 \pm 5.30$ points and ranged from 8 to 36 points. It was shown that the low level of stress was experienced more often by the freshmen $(1$ st year $=13.0 \%$; 2 nd year $=6.1 \%$; 3 rd year $=1.4 \%)$. The average level of stress was experienced more often by sophomores (32.2\%) and juniors (33.3\%) than freshmen (22.8\%). A high level of stress was experienced by slightly more than $60 \%$ freshmen ( 1 st year $=64.2 \%$; 2nd year $=61.7 \%$; 3 rd year $=65.2 \%)$. The differences were statistically significant $(p=0.0281)$ (Table 6).

\section{Strategies of coping with stress used by nursing students - brief COPE}

In difficult situations, students mainly chose the strategy of Active coping $(2.10 \pm 061)$ and Seeking Emotional Support (2.01 \pm 0.76$)$. To a slightly lesser extent, stressful situations were dealt with by Planning $(1.96 \pm 0.65)$ or Seeking Instrumental Support $(1.95 \pm 0.77)$. The least chosen strategy of coping with stress was the Use of Psychoactive Substances strategy $(0.70 \pm 0.92)$.

It was found that the year of studies had a significant impact on the ways of coping with difficult situations by the respondents. In comparison to freshmen and juniors - sophomores were more often, choosing strategies based on active coping (2.25 points), planning (2.09 points), positive reinterpretation (1.84 points), acceptance (1.95 points), and seeking emotional support (2.14 points), doing something else (2.00 points). Juniors, on the other hand, more often than other groups were choosing strategies based on denial (1.22 points),

Table 3 Generalized self-efficacy of nursing students' and year of the study

\begin{tabular}{|c|c|c|c|c|c|c|}
\hline & & & \multicolumn{3}{|c|}{ Year of the study } & \multirow[t]{2}{*}{ Total } \\
\hline & & & $\mathbf{I}$ & II & III & \\
\hline \multirow[t]{6}{*}{ Generalized Self-Efficacy Scale (GSES) } & Low scores & $\mathrm{N}$ & 4 & 7 & 12 & 23 \\
\hline & & $\%$ & $3.3 \%$ & $6.1 \%$ & $17.4 \%$ & $7.5 \%$ \\
\hline & Average scores & $\mathrm{N}$ & 41 & 33 & 31 & 105 \\
\hline & & $\%$ & $33.3 \%$ & $28.7 \%$ & $44.9 \%$ & $34.2 \%$ \\
\hline & High scores & $N$ & 78 & 75 & 26 & 179 \\
\hline & & $\%$ & $63.4 \%$ & $65.2 \%$ & $37.7 \%$ & $58.3 \%$ \\
\hline \multirow[t]{2}{*}{ Total } & & $N$ & 123 & 115 & 69 & 307 \\
\hline & & $\%$ & $100.0 \%$ & $100.0 \%$ & $100.0 \%$ & $100.0 \%$ \\
\hline$x 2=22.174 ; p=0.0002$ & & & & & & \\
\hline
\end{tabular}


Table 4 The sense of satisfaction with the life of the surveyed nursing students and the year of study

\begin{tabular}{|c|c|c|c|c|c|c|}
\hline & & & Year of & & & Total \\
\hline & & & $\mathrm{I}$ & II & III & \\
\hline Satisfaction With Life Scale & Low scores & $\mathrm{N}$ & 32 & 24 & 27 & 83 \\
\hline & & $\%$ & $26.0 \%$ & $20.9 \%$ & $39.1 \%$ & $27.0 \%$ \\
\hline & Average scores & $\mathrm{N}$ & 56 & 44 & 29 & 129 \\
\hline & & $\%$ & $45.5 \%$ & $38.3 \%$ & $42.0 \%$ & $42.0 \%$ \\
\hline & High scores & N & 35 & 47 & 13 & 95 \\
\hline & & $\%$ & $28.5 \%$ & $40.9 \%$ & $18.8 \%$ & $30.9 \%$ \\
\hline Total & & N & 123 & 115 & 69 & 307 \\
\hline & & $\%$ & $100.0 \%$ & $100.0 \%$ & $100.0 \%$ & $100.0 \%$ \\
\hline
\end{tabular}

$\mathrm{X}^{2} \mathrm{chi}^{2}$ independence test, $p$ significance level $<0.05$

discharge (1.70 points), Use of psychoactive substances (1.03 points), discontinuation of activities (1.25 points) ( Table 7).

Moreover, it was found that students chose, above all, strategies based on seeking support $(\mathrm{M}=1.98 ; \mathrm{SD}=0.7)$ and active coping $(\mathrm{M}=1.92 ; \mathrm{SD}=0.52)$, and then Acceptance of situation $(\mathrm{M}=1.77 ; \mathrm{SD}=0.69)$, avoidance behaviour $(\mathrm{M}=1.46 ; \mathrm{SD}=0.47)$ and turning to religion $(M=1.38 ; S D=0.92)$. In difficult situations they reacted to the smallest extend with a sense of humour $(M=1.22$; $\mathrm{SD}=0.72)$ or helplessness $(\mathrm{M}=1.00 ; \mathrm{SD}=0.58)$.

\section{Determinants of the strategies of coping with stress in the surveyed nursing students}

Statistical analysis showed that:

$\triangleright$ The higher the sense of the effectiveness of the students who were subject of the study, the more often they coped with active forms of coping with stress $(\mathrm{rho}=0.343 ; p=0.000)$, seeking support (rho = $0.2 ; p=0.000$ ) and accepted the situation (rho = $0.209 ; p=0.000)$. The lower the sense of effectiveness of the respondents was, the more often they showed a sense of helplessness $($ rho $=-0.22$; $p=0.000)$.

$\triangleright$ The higher was the intensity of stress experienced by students, the more often they coped by avoidance behaviour (rho $=0.21 ; p=0.000$ ) or showing helplessness (rho $=0.2 ; p=0.000$ ). On the other hand, the lower the intensity of stress experienced by students, the more often they were undertaking active forms of coping ( $\mathrm{rho}=-0.16 ; p=0.005$ ).

$\triangleright$ The higher the sense of satisfaction with the life of the surveyed students, the more often they coped by undertaking active forms of coping ( $r h o=0.304 ; p=$ 0.000 ) and seeking support (rho $=0.304 ; p=0.000$ ); while the lower the sense of satisfaction with life, the more often they showed helplessness in a difficult situation (rho $=-0.151 ; p=0.008$ ).

$\triangleright$ On the basis of the analysis, it can also be concluded that the more optimistic the respondents had an attitude to life, the more often they undertook active forms of coping (rho $=0.322 ; p=0.000$ ) or seek support (rho $=0.222 ; p=0.000$ ), while the more their attitude to life was pessimistic, the more often they showed helplessness (rho $=-0.273 ; p=0.000$ ).

Table 5 Assessment of teacher support and hospital stay satisfaction (CLEl-19) versus year of study

\begin{tabular}{llll}
\hline Year of the study & & Teacher support & Satisfaction with clinical placement \\
\hline I & M & 1.68 & 4.36 \\
II & SD & 0.42 & 0.49 \\
& M & 3.28 & 3.33 \\
III & SD & 0.41 & 0.51 \\
& M & 3.30 & 3.33 \\
Total & SD & 0.42 & 0.60 \\
& M & 2.64 & 3.75 \\
P & SD & 0.89 & 0.73 \\
\hline
\end{tabular}

$M$ mean, SD standard deviation, $p$ significance level $<0.05$ 
Table $\mathbf{6}$ Intensification of stress experienced by students and the year of study

\begin{tabular}{|c|c|c|c|c|c|c|}
\hline & & & Year of & & & Total \\
\hline & & & $\mathrm{I}$ & II & III & \\
\hline Perceived Stress Scale (PSS-10) & Low scores & $\mathrm{N}$ & 16 & 7 & 1 & 24 \\
\hline & & $\%$ & $13.0 \%$ & $6.1 \%$ & $1.4 \%$ & $7.8 \%$ \\
\hline & Average scores & $N$ & 28 & 37 & 23 & 88 \\
\hline & & $\%$ & $22.8 \%$ & $32.2 \%$ & $33.3 \%$ & $28.7 \%$ \\
\hline & High scores & $N$ & 79 & 71 & 45 & 195 \\
\hline & & $\%$ & $64.2 \%$ & $61.7 \%$ & $65.2 \%$ & $63.5 \%$ \\
\hline Total & & $\mathrm{N}$ & 123 & 115 & 69 & 307 \\
\hline & & $\%$ & $100.0 \%$ & $100.0 \%$ & $100.0 \%$ & $100.0 \%$ \\
\hline$p$ & & & 0.0281 & & & \\
\hline
\end{tabular}

$p$ significance level $<0.05$

$>$ The higher the level of satisfaction of the surveyed students with their stay in the hospital ward, the more often they coped by seeking support (rho $=0.128 ; p=$ 0.025). On the other hand, the lower the sense of satisfaction with the stay in the hospital ward, the more often they coped by the sense of humour (rho $=-$

$0.173 ; p=0.002$ ) or showing helplessness (rho $=-0.114$; $p=0.045)$ (Table 8$)$.

Variables determining the choice of coping strategies of nursing students - linear regression

Linear regression using the stepwise method was calculated on the sums of individual scales. This applies to all scales, i.e.: GSES, SWLS, LOT-R, CLEI, PSS-10. For the Sense of Humour strategy, none of the explanatory variables were significant, and therefore there were no variables in the model.

Active coping was chosen significantly more often by students with a higher sense of self-efficacy (beta $=$ 0.274) and a higher level of dispositional optimism (beta $=0.194)$. Planning was more often chosen by students of older years (beta $=0.116$ ) with a higher sense of self-efficacy (beta $=0.194$ ) and a higher sense of satisfaction with life (beta $=0.166$ ). The positive reevaluation was a strategy that was more often used by students with a higher sense of life satisfaction (beta $=0.210$ ), a higher level of dispositional optimism (beta $=0.150$ ), and a higher sense of self-efficacy (beta $=0.143$ ) who received more support from the teacher (beta $=0.130$ ). Acceptance was a strategy that was more often chosen by students with a higher sense of life satisfaction (beta $=$

Table 7 Strategies of coping with stress used by nursing students and the year of study

\begin{tabular}{|c|c|c|c|c|c|c|c|c|c|}
\hline \multirow[t]{2}{*}{ Strategy } & \multicolumn{2}{|c|}{ Total } & \multicolumn{2}{|c|}{ I year } & \multicolumn{2}{|c|}{ II year } & \multicolumn{2}{|c|}{ III year } & \multirow[t]{2}{*}{$p$} \\
\hline & M & SD & M & SD & M & SD & M & SD & \\
\hline Active Coping & 2.10 & 0.61 & 2.07 & 0.63 & 2.25 & 0.59 & 1.92 & 0.57 & 0.0005 \\
\hline Planning & 1.96 & 0.65 & 1.85 & 0.68 & 2.09 & 0.63 & 1.92 & 0.63 & 0.0111 \\
\hline Positive Reinterpretation & 1.71 & 0.69 & 1.60 & 0.70 & 1.84 & 0.66 & 1.67 & 0.68 & 0.0259 \\
\hline Acceptation & 1.77 & 0.69 & 1.63 & 0.70 & 1.95 & 0.67 & 1.74 & 0.65 & 0.0005 \\
\hline Sense of Humour & 1.22 & 0.72 & 1.07 & 0.75 & 1.25 & 0.69 & 1.44 & 0.63 & 0.0006 \\
\hline Turning Towards Religion & 1.38 & 0.92 & 1.27 & 0.91 & 1.48 & 1.01 & 1.41 & 0.79 & 0.2077 \\
\hline Seeking Emotional Support & 2.01 & 0.76 & 1.98 & 0.74 & 2.14 & 0.79 & 1.87 & 0.73 & 0.0236 \\
\hline Seeking Instrumental Support & 1.95 & 0.77 & 1.93 & 0.84 & 2.04 & 0.70 & 1.84 & 0.75 & 0.1659 \\
\hline Finding Other Activities & 1.81 & 0.68 & 1.74 & 0.68 & 2.00 & 0.69 & 1.64 & 0.57 & 0.0001 \\
\hline Denial & 1.04 & 0.76 & 1.01 & 0.79 & 0.96 & 0.78 & 1.22 & 0.66 & 0.0191 \\
\hline Discharge & 1.54 & 0.68 & 1.45 & 0.71 & 1.53 & 0.66 & 1.70 & 0.65 & 0.0403 \\
\hline Use of Psychoactive Substances & 0.70 & 0.92 & 0.65 & 1.02 & 0.55 & 0.79 & 1.03 & 0.89 & 0.0004 \\
\hline Cessation of Activity & 0.92 & 0.77 & 0.84 & 0.78 & 0.82 & 0.71 & 1.25 & 0.76 & 0.0001 \\
\hline Self-blame & 1.39 & 0.73 & 1.46 & 0.76 & 1.30 & 0.69 & 1.43 & 0.71 & 0.2782 \\
\hline
\end{tabular}

$M$ mean, SD standard deviation, $p$ significance level $<0.05$ 
Table 8 Variables determining strategies undertaken by nursing students to cope with stress

\begin{tabular}{|c|c|c|c|c|c|c|c|}
\hline \multirow{2}{*}{$\begin{array}{l}\text { Coping strategy } \\
\text { Active Coping }\end{array}$} & \multicolumn{2}{|c|}{ Self-efficacy } & \multirow{2}{*}{$\begin{array}{l}\text { Perceived stress } \\
-0.140\end{array}$} & \multirow{2}{*}{$\begin{array}{l}\text { Life satisfaction } \\
0.188\end{array}$} & \multirow{2}{*}{$\begin{array}{l}\text { Dispositional } \\
\text { optimism } \\
0.285\end{array}$} & \multirow{2}{*}{$\begin{array}{l}\begin{array}{l}\text { Satisfaction with } \\
\text { clinical placement }\end{array} \\
0.033\end{array}$} & \multirow{2}{*}{$\begin{array}{l}\text { Teacher support } \\
0.051\end{array}$} \\
\hline & rho & 0.337 & & & & & \\
\hline & $p$ & 0.0000 & 0.0142 & 0.0009 & 0.0000 & 0.5702 & 0.3742 \\
\hline \multirow[t]{2}{*}{ Planning } & rho & 0.230 & -0.106 & 0.216 & 0.213 & 0.109 & -0.061 \\
\hline & $p$ & 0.0000 & 0.0628 & 0.0001 & 0.0002 & 0.0559 & 0.2872 \\
\hline \multirow[t]{2}{*}{ Positive Reevaluation } & rho & 0.252 & -0.135 & 0.312 & 0.258 & 0.142 & 0.055 \\
\hline & $p$ & 0.0000 & 0.0178 & 0.0000 & 0.0000 & 0.0127 & 0.3342 \\
\hline \multirow[t]{2}{*}{ Acceptation } & rho & 0.209 & -0.092 & 0.220 & 0.203 & 0.168 & -0.067 \\
\hline & $p$ & 0.0002 & 0.1059 & 0.0001 & 0.0003 & 0.0032 & 0.2389 \\
\hline \multirow[t]{2}{*}{ Sense of Humour } & rho & -0.017 & -0.032 & 0.042 & -0.119 & 0.100 & -0.173 \\
\hline & $p$ & 0.7673 & 0.5756 & 0.4680 & 0.0379 & 0.0792 & 0.0023 \\
\hline \multirow[t]{2}{*}{ Turning Towards Religion } & rho & 0.053 & -0.041 & 0.075 & -0.015 & 0.106 & -0.074 \\
\hline & $p$ & 0.3575 & 0.4735 & 0.1928 & 0.7991 & 0.0644 & 0.1942 \\
\hline \multirow[t]{2}{*}{ Seeking Emotional Support } & rho & 0.201 & -0.048 & 0.280 & 0.184 & 0.071 & 0.102 \\
\hline & $p$ & 0.0004 & 0.3993 & 0.0000 & 0.0012 & 0.2125 & 0.0730 \\
\hline \multirow[t]{2}{*}{ Seeking Instrumental Support } & rho & 0.162 & -0.101 & 0.282 & 0.228 & 0.070 & 0.129 \\
\hline & $p$ & 0.0044 & 0.0764 & 0.0000 & 0.0001 & 0.2182 & 0.0240 \\
\hline \multirow[t]{2}{*}{ Finding Other Activities } & rho & 0.224 & 0.115 & 0.031 & 0.036 & 0.165 & -0.022 \\
\hline & $p$ & 0.0001 & 0.0444 & 0.5842 & 0.5320 & 0.0037 & 0.6993 \\
\hline \multirow[t]{2}{*}{ Denial } & rho & -0.109 & 0.139 & -0.047 & -0.242 & 0.000 & -0.061 \\
\hline & $\mathrm{p}$ & 0.0570 & 0.0151 & 0.4115 & 0.0000 & 0.9981 & 0.2838 \\
\hline \multirow[t]{2}{*}{ Discharge } & rho & 0.019 & 0.178 & 0.054 & -0.108 & 0.086 & -0.045 \\
\hline & $p$ & 0.7468 & 0.0018 & 0.3498 & 0.0579 & 0.1327 & 0.4348 \\
\hline \multirow[t]{2}{*}{ Use Psychoactive Substances } & rho & -0.097 & 0.033 & -0.021 & -0.160 & 0.008 & -0.149 \\
\hline & $p$ & 0.0914 & 0.5622 & 0.7167 & 0.0048 & 0.8897 & 0.0089 \\
\hline \multirow[t]{2}{*}{ Cessation of Activity } & rho & -0.263 & 0.136 & -0.060 & -0.206 & 0.085 & -0.127 \\
\hline & $p$ & 0.0000 & 0.0173 & 0.2967 & 0.0003 & 0.1377 & 0.0259 \\
\hline \multirow[t]{2}{*}{ Self- blaming } & rho & -0.140 & 0.300 & -0.230 & -0.246 & -0.032 & -0.023 \\
\hline & $p$ & 0.0143 & 0.0000 & 0.0000 & 0.0000 & 0.5820 & 0.6860 \\
\hline
\end{tabular}

rho Spearman's rank correlation coefficient, $p$ significance level $p<0.05$

0.175 ), a higher sense of self-efficacy (beta $=0.152$ ), who received more support from the teacher (beta $=0.156$ ). Older students significantly more often coped with their sense of humour (beta $=0.199$ ). Seeking emotional support was a strategy chosen more often by students with a higher level of life satisfaction (beta $=0.212$ ), and a higher sense of self-efficacy (beta $=0.124$ ). Seeking instrumental support was significantly more often chosen by students with a higher sense of life satisfaction (beta = 0.288). Focusing on doing something else as a coping strategy was chosen more often by younger students (beta $=-0.268$ ), who experienced the higher intensity of stress $($ beta $=0.163)$, who received more support $($ beta $=$ 0.364 ), and had a higher sense of self-efficacy (beta = 0.217). Students with a lower sense of dispositional optimism coped significantly more often by denial. (beta = -
0.233). The discharge strategy was significantly more often chosen by students of older years (beta $=0.127$ ) with a higher level of life satisfaction (beta $=0.172)$ experiencing more intense stress (beta $=0.254$ ). Older students (beta $=0.323$ ) receiving less teacher support (beta $=-0.248$ ) were significantly more likely to cope with the use of psychoactive substances. Cessation of activities was a coping strategy chosen more often by students of older years (beta $=0.138$ ) with a lower sense of self-efficacy (beta $=-0.224$ ). Students with a lower sense of dispositional optimism (beta $=-0.174$ ) experiencing higher levels of stress (beta $=0.210$ ) were significantly more likely to blame themselves. Due to the multiplicity of the factors compared, it was decided to present statistically significant variables in Table 9. 
Table 9 Variables determining choice of coping strategy of the respondents

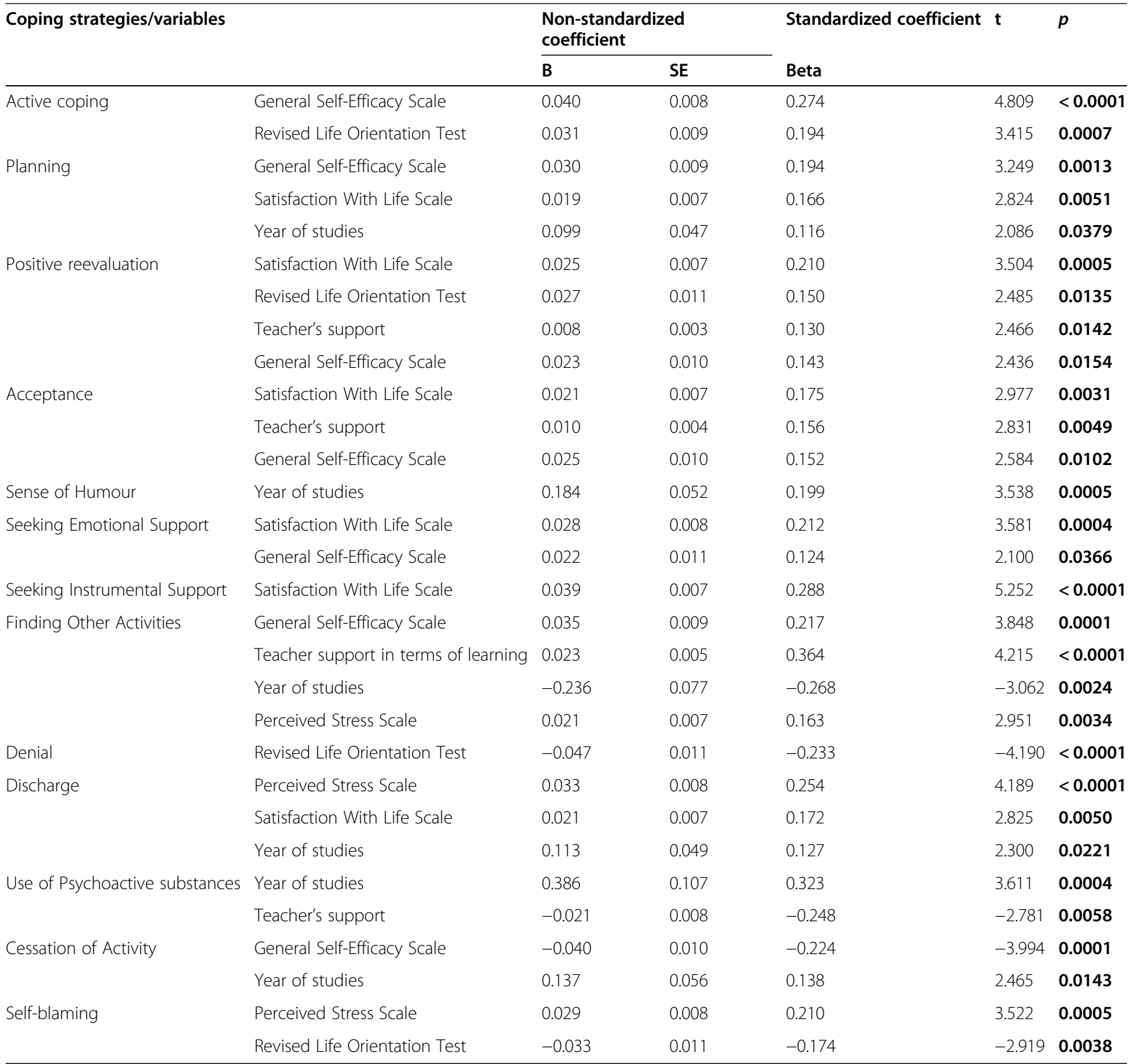

$B$ non-standardized regression coefficient, SE standard error, Beta standardized regression coefficient, $t$ test $\mathrm{t}, p$ significance level $<0.05$

\section{Discussion}

This study have attempted to evaluate how Polish students are coping with stress in terms of clinical learning. The nature and quality of the student's clinical experience, besides the transfer of knowledge is extremely important during the process of educating nursing students and shaping professional competences.

Stress is present in the lives of students throughout the education process, especially in clinical training [15, 16]. More than half of the students in the presented study felt stress of high intensity. Similar results were obtained by other researchers $[8,9,16,41]$. Students undertake differentiated strategies of coping with stress in difficult situations. In this study, the respondents mainly chose the strategies of Active Coping and Seeking Emotional Support, and to a lesser extent Planning or Seeking Instrumental Support strategies. These results are consistent with the results obtained by other researchers [41-43]. Polish students revealed a greater intensity of the assessed remedial and adaptation strategies, i.e. Active Coping and Planning, than students from Spain or Slovakia [44]. Students from the presented study, however, less frequently used the avoidance strategy based on Psychoactive Substances, which has negative consequences on health. These results are consistent with the conclusions of other authors [14, 
45]. In contrast, students from Spain obtained higher intensity of the strategies assessed, i.e. Use of Psychoactive Substances, Cessation of Activity and Self-blame, than Polish and Slovakian students [44].

Research conducted by Fornès-Vives et al. [14] showed that coping mechanisms and personality changes experienced by nursing students throughout their degree program seem to mirror the professional competencies needed by future licensed nurses. The results of the research carried out by Kaneko and Momino [5] allowed for the conclusion that in difficult situations, students were inactive in seeking help for solving problems. However, in the studies [42], nursing students displayed avoidance behaviour in stressful situations.

The authors' own research showed that students experiencing a higher level of stress more often coped with it by Finding other activities, Discharging, Cessation activity or Self-blame. These results are consistent with the results obtained by other authors $[8,45,46]$.

It was found that the year of studies had a significant impact on the nursing students' stress coping strategies. Second-year students, to a greater extent than first-year and third-year students, chose strategies based on Active Coping, Planning, and Positive Reevaluation.

Nursing students in their senior level [47, 48] and those with a high level of self-efficacy [49] tended to use a problem-solving approach.

People with a higher sense of self-efficacy more often coped with stress through Active Counseling, Planning, Positive Reevaluation, Acceptance, Seeking Emotional Support, and Seeking Instrumental Support, similarly to other studies [22, 50]. Dealing with stress depends largely on personality variables influencing the choice of coping strategies [51].

A high and average level of optimism was displayed by the majority of the surveyed nursing students. People with a higher level of dispositional optimism significantly more often coped with stress through Active Coping, Positive Reevaluation, Planning, Acceptance, Seeking Emotional Support, and Seeking Instrumental Support. These results are consistent with other authors' results [45]. A low level of optimism in the surveyed nursing students was significantly associated with more frequent coping through Denial, Ceasing Action, Self-blame, or Use of Psychoactive Substances. Research by Soares et al. [52] confirms the existence of a relationship between low optimism and the use of psychoactive substances. However, a more reactive emotion focused coping approach, defined as a strong emotional reaction, distortion, and impulsivity, is associated with reducing satisfaction with school and life. Cruz et al. [27] as well as Sohl and Moyer [48] indicated that optimism and proactive coping with stress at work positively influenced the quality of life.
The studies of Yildirim et al. [42] show that support is a determinant of coping with stress in nursing students. They emphasize the legitimacy of effective interventions counteracting educational stress, which would not only favour the development of skills, but also reduce its negative health effects. Other authors also pointed to the significant importance of support in strengthening positive self-image [52, 53], or mobilization to fight stress $[54,55]$. In the conducted research, it was unequivocally shown that students who felt greater support from the teacher significantly more often "looked for instrumental support". The results of the research conducted by Siu Yin Ching et al. [31] indicated the need to support, in particular, students undertaking coping strategies based on Self-blame.

Students who were more satisfied with their stay in the ward significantly more often coped with stress through Acceptance, Finding Other Activities, and Positive Reevaluation. The existence of the relationship between stress experienced by students during academic education and coping with it and satisfaction with life was demonstrated by Lardier et al. [29].

\section{Limitations of the study}

The main limitations of the study are related to areas of data collection methods. Data collection was undertaken at one point in time rather than longitudinally. The characteristics of the participants - young people, mainly women - could represent a bias.

The selection of the group of respondents was deliberate, the research was carried out at one university, the conclusions cannot be applied to the general population. More research is needed.

\section{Strengths of the study}

The results of the multivariate analysis of the influence of selected variables on coping with stress in nursing students allowed for the identification of the determinants of coping with stress during clinical education especially in times of stress.

Understanding the influence of psychosocial components on the coping strategies of Polish nursing students is important for several reasons. Firstly, the ability to cope with stress, appropriately shaped throughout education can influence the development of a positive professional identity and attitudes towards a future profession. Secondly, ensuring the nursing students have favourable conditions for education, using and strengthening their personal resources can have an effect on the learning results and indirectly on the quality of their care and safety of patients. Additionally, the ability to cope with stress at work will be more effective in preventing burnout, to which nurses are vulnerable due to the nature of their profession. 


\section{Conclusions}

All the variables had a significant impact on coping with stress: the level of perceived stress, disposable optimism, sense of self-efficacy, sense of life satisfaction, as well as satisfaction with the stay in a hospital ward, support received from the teacher and the year of the study.

Active strategies of coping with stress were used significantly more often by the respondents with a greater sense of self-efficacy, a greater sense of life satisfaction, and disposable optimism. Students experiencing more teacher support significantly were more often seeking instrumental support. Avoidance strategies of coping with stress were used by the respondents with low selfefficacy, low level of disposable optimism, low sense of life satisfaction, and not a lot of teacher support. Students who did not receive a lot of support from the teacher and those with a low level of dispositional optimism significantly more often used psychoactive substances. The greater intensity of stress perceived by nursing students' determined more frequent avoidance behaviour.

The results of the research have allowed the identification of the needs in the field of strengthening the personal resources of nursing students. In the future, they may form the basis for the development of educational programs aimed at developing coping skills in various groups of nursing students. More intervention studies on stress management are also needed.

\section{Acknowledgements}

The authors thank the students who took part in the study, for their patience answering questionnaires. Without their help and support this paper would not have been possible.

\section{Authors' contributions}

Conceptualization, I.B-C.; methodology, I.B-C., A.M., J.Z-P. formal analysis, I.B-C. investigation, I. B-C., E.Z;; resources I.B-C.; data curation, I.B-C.; writing-original draft preparation, I.B-C., A.M., J.Z-P., A.K., E.Z.; writing-review and editing, I.B-C., A.K.; supervision, I. B-C., J.Z-P.; project administration, I.B-C.; funding acquisition, I.B-C. All authors have read and agreed to the published version of the manuscript.

\section{Funding}

Not applicable.

\section{Availability of data and materials}

The datasets used and analysed during the current study are available from the correspondent author based on reasonable request.

\section{Declarations}

\section{Ethics approval and consent to participate}

The research was approved by the Jagiellonian University Bioethics Committee - No. of approval: 072.6120.208.2018. Students were informed of the confidentiality and anonymity of the study. They were also told that their participation was voluntary and that they may withdraw from the study at any time. Students had given their informed verbal consent to participate in the study according to research procedure accepted by Bioethics Committee.

\section{Consent for publication}

Not applicable.

\section{Competing interests}

The author declare no competing interest.

Received: 17 November 2020 Accepted: 8 June 2021

Published online: 12 July 2021

\section{References}

1. Sęk H, Cieślak R. Wsparcie społeczne - sposoby definiowania, rodzaje i źródła wsparcia, wybrane koncepcje teoretyczne. In: Sęk H, Cieślak R, editors. Wsparcie społeczne, stres i zdrowie. Warszawa: Wydawnictwo Naukowe PWN; 2004. p. 11-28.

2. Ramli NHH, Alavi M, Mehrinezhad SA, Ahmadi A. Academic stress and selfregulation among university students in Malaysia: mediator role of mindfulness. Behav Sci. 2018;8(1):12-20. https://doi.org/10.3390/bs8010012

3. Drew BL, Motter T, Ross R, Goliat L, Sharpnack P, Govoni A, et al. Care for the caregivers: evaluation of mind-body self-care for accelerated nursing students. Holist Nurs Pract. 2016;30(3):148-54. https://doi.org/10.1097/HNP. 0000000000000140.

4. Akhu-Zaheya LM, Shaban IA, Wejdan AK. Nursing students' perceived stress and influences in clinical performance. J Adv Nurs Stud. 2015;4:44-8. https:// doi.org/10.14419/ijans.v4i2.4311.

5. Kaneko S, Momino K. Stress factors and coping behaviors in nursing students during Fundamentals Clinical Training in Japan. Int J Nurs Clin Pract. 2015;2:138-44. https://doi.org/10.15344/2394-4978/2015/138.

6. Wolf $L$, Stidham AW, Ross R. Predictors of stress and coping strategies of US accelerated vs. generic baccalaureate nursing students: an embedded mixed methods study. Nurse Educ Today. 2015;35(1):201-5. https://doi.org/1 0.1016/j.nedt.2014.07.005.

7. Dev Bhurtun H, Turunen H, Estola M, Saaranen T. Changes in stress levels and coping strategies among Finnish nursing students. Nurse Educ Pract. 2021;50:102958. https://doi.org/10.1016/j.nepr.2020.102958.

8. Bodys-Cupak I, Majda A, Grochowska A, Zalewska-Puchała J, Kamińska A, Kuzera G. Patient-related stressors and coping strategies in baccalaureate nursing students during clinical practice. Med Stud. 2019;35(1):41-7. https:// doi.org/10.5114/ms.2019.84050.

9. Bodys-Cupak I, Grochowska A, Zalewska-Puchała J, Majda A. Stress and coping strategies of medical students during their first clinical practice - a pilot study. Med Stud. 2019;35(4):294-303. https://doi.org/10.5114/ms.2019. 91247.

10. Lazarus RS, Folkman S. Stress, appraisal, and coping; 1984.

11. Folkman S, Lazarus RS, Gruen RJ, DeLongis A. Appraisal, coping, health status, and psychological symptoms. J Pers Soc Psychol. 1986;50(3):571-9. https://doi.org/10.1037/0022-3514.50.3.571.

12. Folkman S, Lazarus RS, Dunkel-Schetter C, DeLongis A, Gruen RJ. Dynamics of a stressful encounter: cognitive appraisal, coping, and encounter outcomes. J Pers Soc Psychol. 1986;50(5):992-1003. https://doi.org/10.1037/ 0022-3514.50.5.992.

13. Carver CS, Scheier MF, Weintraub JK. Assessing coping strategies: a theoretically-based approach. J Pers Soc Psychol. 1989;56(2):267-83. https:// doi.org/10.1037//0022-3514.56.2.267.

14. Fornés-Vives J, Garcia-Banda G, Frias-Navarro D, Rosales-Viladrich G. Coping, stress, and personality in Spanish nursing students: a longitudinal study. Nurse Educ Today. 2016;36:318-23. https://doi.org/10.1016/j.nedt.2015.08. 011.

15. Labrague LJ, McEnroe-Petitte DM, Al Amri M, Fronda DC, Obeidat AA. An integrative review on coping skills in nursing students: implications for policymaking. Int Nurs Rev. 2018;65(2):279-91. https://doi.org/10.1111/ inr.12393.

16. McCarthy B, Trace A, O'Donovan M, Brady-Nevin C, Murphy M, O'Shea M, et al. Nursing and midwifery students' stress and coping during their undergraduate education programmes: an integrative review. Nurse Educ Today. 2018;61:197-209. https://doi.org/10.1016/j.nedt.2017.11.029.

17. Adiele D, Judith CA, Morgan GP, Catherine B, Carolyne LM. Association of academic stress, anxiety and depression with social-demographic among medical students. Int J Soc Sci Stud. 2018;6:27-32. https://doi.org/10.11114/ ijsss.v6i6.3288.

18. Deb S, Strodl E, Sun J. Academic stress, parental pressure, anxiety and mental health among Indian high school students. Int J Psych Behav Sci. 2015;5:26-34. https://doi.org/10.5923/j.jpbs.20150501.04.

19. Lecca LI, Portoghese I, Mucci N, Galletta M, Meloni F, Pilia I, et al. Association between work-related stress and QT prolongation in male 
workers. Int J Res Public Health. 2019;16(23):4781. https://doi.org/10.3390/ ijerph16234781.

20. Kowalczuk K, Krajewska-Kułak E, Sobolewski M. Working excessively and burnout among nurses in the context of sick leaves. Front Psychol. 2020;11: 285. https://doi.org/10.3389/fpsyg.2020.00285.

21. Juczyński Z. Narzędzia pomiaru w promocji i psychologii zdrowia. Warszawa: Pracownia Testów Psychologicznych Polskiego Towarzystwa Psychologicznego; 2012.

22. Bodys-Cupak I, Majda A, Zalewska-Puchała J, Kamińska A. The impact of a sense of self-efficacy on the level of stress and the ways of coping with difficult situations in Polish nursing students. Nurse Educ Today. 2016;45: 102-7. https://doi.org/10.1016/j.nedt.2016.07.04.

23. Shoji K, Cieslak R, Smoktunowicz E, Rogala A, Benight CC, Luszczynska A. Associations between job burnout and self-eficacy: a meta-analysis. Anxiety Stress Coping. 2016;29(4):367-86. https://doi.org/10.1080/10615806.2015.1 058369

24. Molero MM, Pérez-Fuentes MC, Gázquez JJ, Simón MM, Martos A. Burnout risk and protection factors in certified nursing aides. Int J Environ Res Public Health. 2018;15(6):1116. https://doi.org/10.3390/ijerph15061116.

25. Delany C, Miller K, El-Ansary D, Remedios L, Hosseini A, McLeod S. Replacing stressful challenges with positive coping strategies: a resilience program for clinical placement learning. Adv in Health Sci Educ. 2015;20(5): 1303-24. https://doi.org/10.1007/s10459-015-9603-3.

26. Chang Y, Chan HJ. Optimism and proactive coping in relations to burnout among nurses. J Nurs Manag. 2015;23(3):401-8. https://doi.org/10.1111/ jonm.12148.

27. Cruz JP, Neil D, Cabrera DNC, Hufana OD, Alquwez N, Almazan J. Optimism, proactive coping and quality of life among nurses: a cross-sectional study. J Clin Nurs. 2018;27(9-10):2098-108. https://doi.org/10.1111/jocn.14363.

28. Admi H, Moshe-Eilon Y, Sharon D, Mann M. Nursing students' stress and satisfaction in clinical practice along different stages: a crosssectional study. Nurse Educ Today. 2018;68:86-92. https://doi.org/10.101 6/j.nedt.2018.05.027.

29. Lardier DT, Lee C-YS, Rodas JM, Garcia-Reid P, Reid RJ. The effect of perceived college-related stress on depression, life satisfaction, and school satisfaction: the coping strategies of Hispanic college students from a Hispanic serving institution. Educ Urban Soc. 2020;52(8):1204-22. https://doi. org/10.1177/0013124519896845.

30. Bisholt B, Ohlsson U, Engstrom AK, Johanssen AS, Gustafsson M. Nursing students' assessment of the learning environment in different clinical settings. Nurse Educ Pract. 2014;14(3):304-10. https://doi.org/10.1016/j/ nepr.2013.11.005.

31. Chinga SSY, Cheungb K, Hegneyc D, Reese CS. Stressors and coping of nursing students in clinical placement: A qualitative study contextualizing their resilience and burnout. Nurse Educ Pract. 2020;42:102690. https://doi. org/10.1016/j.nepr.2019.102690.

32. Scheier MF, Carver CS, Bridges MW. Distinguishing optimism from neurotism (and trait anxiety, self-mastery, and self-esteem): a reevaluation of life orientation test. J Pers Soc Psychol. 1994;67(6):1063-78. https://doi.org/1 0.1037/0022-3514.67.6.1063

33. Schwarzer R. Measurement of perceived self-efficacy: psychometric scales for cross-cultural research. Berlin: Freie Universität Berlin, Intitute für Psychologie; 1993

34. Diener E, Emmons RA, Larson RJ, Griffin S. The satisfaction with life scale. J Pers Assess. 1985:49(1):71-5. https://doi.org/10.1207/s15327752jpa4901_13.

35. Salamonson $Y$, Bourgeois $S$, Everett $B$, Weaver R, Peters K, Jackson D. Psychometric testing of the abbreviated clinical learning environment inventory (CLEl-19). J Adv Nurs. 2011;67(12):2668-76. https://doi.org/1 0.1111/j.1365-2648.2011.05704.x.

36. Cohen S, Kamarck T, Memelstain R. A global measure of perceived stress. $J$ Health Soc Behav. 1983;24:386-96.

37. Juczyński Z, Ogińska-Bulik N. Narzędzia do pomiaru stresu i radzenia sobie ze stresem. Warszawa: Pracownia Testów Psychologicznych Polskiego Towarzystwa Psychologicznego; 2012

38. R Core Team R. A language and environment for statistical computing. $R$ Foundation for Statistical Computing, Vienna, Austria, 2019. URL https:// www.R-project.org/.

39. Regulation of the European Parliament and of the Council (EU) 2016/679 of 27th April 2016. On the Protection of Individuals with Regard to the Processing of Personal Data and on the Free Movement of Such Data and the Repeal of Directive 95/46/EC (General Data Protection Regulation).
Available online: https://eur-lex.europa.eu/legal-content/PL/TXT/?uri= CELEX\%3A32016R0679 (Accessed on 7 Jan 2019).

40. The Act of 10th May 2018 on the protection of personal data. Dz.U. 2018 poz. 1000). Available online: http://prawo.sejm.gov.pl/isap.nsf/DocDetails. xsp?id=WDU20180001000 (Accessed on 7 Jan 2019).

41. Mi-Ran K, Su-Jeong H. Nursing students' emotional intelligence and coping strategies. Adv Sci Technol Lett. 2015;88:53-6. https://doi.org/10.14257/astl.2 015.88.11.

42. Yildirim N, Karaca A, Cangur S, Acikgoz F, Akkus D. The relationship between educational stress, stress coping, self-esteem, social support, and health status among nursing students in Turkey: a structural equation modeling approach. Nurse Educ Today. 2017;48:33-9. https://doi.org/10.1016/j.nedt.2 016.09.014.

43. Bamuhair SS, Al Farhan Al, Althubaiti A, Agha S, Rahman S, Ibrahim NO. Sources of stress and coping strategies among undergraduate medical students enrolled in a problem-based learning curriculum. J Biomed Educ. 2015;2015:1-8. https://doi.org/10.1155/2015/575139.

44. Kupcewicz E, Grochans E, Kudačáková H, Mikla M, Jóźwik M. Analysis of the relationship between stress intensity and coping strategy and the quality of life of nursing students in Poland, Spain and Slovakia. Int J Res Public Health. 2020;17(12):4536-52. https://doi.org/10.3390/ijerph17124536.

45. Joseph N, Nallapati A, Machado MX, Nair V, Matelez S, Muthusamy N, et al. Assessment of academic stress and its coping mechanisms among medical undergraduate students in a large Midwestern University. Curr Psychol. 2020;40(6):2599-609. https://doi.org/10.1007/s12144-020-00963-2.

46. Karacaa A, Yildirima N, Cangurb S, Acikgoza F, Akkusa D. Relationship between mental health of nursing students and coping, selfesteem and social suport. Nurse Educ Today. 2019;76:44-50. https://doi.org/10.1016/j. nedt.2019.01.029.

47. Chan CK, So WK, Fong DY. Hong Kong baccalaureate nursing students' stress and their coping strategies in clinical practice. J Prof Nurs. 2009;25(5): 307-13. https://doi.org/10.1016/.jprofnurs.2009.01.018.

48. Sohl SJ, Moyer A. Refining the conceptualization of a future-oriented selfregulatory behavior: proactive coping. Pers Individ Differ. 2009;47(2):139-44. https://doi.org/10.1016/j.paid.2009.02.013.

49. Zhao FF, Lei XL, He W, Gu JH, Li DW. The study of perceived stress, coping strategy and self-efficacy of Chinese undergraduate nursing students in clinical practice. Int J Nurs Pract. 2014;21:401-9.

50. Hirsch CD, Barlem ELD, Tomaschewski-Barlem JG, Fiqueira AB, Lunardi VL, Oliveira AC. Predictors of stress and coping strategies adopted by nursing students. Acta Paul Enferm. 2014;28(3):224-9. https://doi.org/10.1590/1982019401500038.

51. Gou WH, Sun WJ, Chen DD, Zhang Z, Zhao JX, Zhang Y, et al. Coping selfefficacy of nursing undergraduates with problem-based curricula. Contemp Nurse. 2019;55(4-5):288-302. https://doi.org/10.1080/10376178.2018.1537719.

52. Soares MH, Luís MAV, Corradi-Webster CM, Martins JT, Gonçalves Pestana Hirata A. Psychological concept of optimism and drug use among nursing students. Acta Paul Enferm. 2011;24(3):393-9. https://doi.org/10.1590/S01 03-21002011000300014.

53. Dąbska O, Wołoszynek E, Kowalczyk A, Kozłowska E. Ways of coping with stress: Survey based on the group of students from selected universities in Lublin. Piel Zdr Publ. 2017;26:27-34. https://doi.org/10.17219/pzp/64695.

54. Li J, Han X, Wang W, Sun G, Cheng Z. How social support influences university students' academic achievement and emotional exhaustion: the mediating role of self-esteem. Learn Indiv Differ. 2018;61:120-6. https://doi. org/10.1016/j.lindif.2017.11.016

55. Wongtongkam N. Influence of coping, self-esteem and social support on undergraduate students' emotional distress. Health Educ. 2019;119(3):187201. https://doi.org/10.1108/HE-01-2019-0001.

\section{Publisher's Note}

Springer Nature remains neutral with regard to jurisdictional claims in published maps and institutional affiliations. 